\title{
Article \\ Multi-Objective Optimal Integration of Solar Heating and Heat Storage into Existing Fossil Fuel-Based Heat and Power Production Systems
}

\author{
Guangxuan Wang ${ }^{1,2, *(\mathbb{D})}$ and Julien Blondeau ${ }^{1,2}$ (D)
}

Citation: Wang, G.; Blondeau, J. Multi-Objective Optimal Integration of Solar Heating and Heat Storage into Existing Fossil Fuel-Based Heat and Power Production Systems. Energies 2022, 15, 1942. https:// doi.org/10.3390/en15051942

Academic Editors: Francesco Calise and Hee-Je Kim

Received: 13 December 2021

Accepted: 1 March 2022

Published: 7 March 2022

Publisher's Note: MDPI stays neutral with regard to jurisdictional claims in published maps and institutional affiliations.

Copyright: (c) 2022 by the authors. Licensee MDPI, Basel, Switzerland. This article is an open access article distributed under the terms and conditions of the Creative Commons Attribution (CC BY) license (https:/ / creativecommons.org/licenses/by/ $4.0 /)$.
1 Thermo and Fluid Dynamics (FLOW), Faculty of Engineering, Vrije Universiteit Brussel (VUB), Pleinlaan 2, 1050 Brussels, Belgium; julien.blondeau@vub.be

2 Brussels Institute for Thermal-Fluid Systems and Clean Energy (BRITE), Vrije Universiteit Brussel (VUB) and Université Libre de Bruxelles (ULB), 1050 Brussels, Belgium

* Correspondence: guangxuan.wang@vub.be

\begin{abstract}
Increasing the share of Renewable energy sources in District Heating (DH) systems is of great importance to mitigate their $\mathrm{CO}_{2}$ emissions. The combined integration of Solar Thermal Collectors (STC) and Thermal Energy Storage (TES) into existing Combined Heat and Power (CHP) systems can be a very cost-effective way to do so. This paper aims at finding the optimal design of STC and TES systems integrated in existing CHP's considering two distinct objectives: economic profitability and environmental impact. To do so, we developed a three-stage framework based on Pareto-optimal solutions generated by multi-objective optimization, a Technique for Order Preference by Similarity to Ideal Solution (TOPSIS)-entropy method to select the optimal solution, followed by the definition of final Operation strategy. We proposed relevant improvement of the state-of-theart models used in similar analysis. We also applied the proposed methodology to the case of a representative, $12 \mathrm{MW}_{\text {th }} \mathrm{CHP}$ plant. Our results show that, while the addition of TES or STC alone results in limited performances and/or higher costs, both the cost and the $\mathrm{CO}_{2}$ emissions can be reduced by integrating the optimal combination of STC and TES. For the selected, optimal solution, carbon emissions are reduced by $10 \%$, while the Annual Total Cost $(A T C)$ is reduced by $3 \%$. It also improves the operational flexibility and the efficiency by peak load shaving, load valley filling and thus by decreasing the peak load boiler operation. Compared to the addition of STC alone, the use of TES results in an increased efficiency, from $88 \%$ to $92 \%$. The optimal share of STC is then increased from $7 \%$ to $10 \%$.
\end{abstract}

Keywords: combined heat and power; thermal storage; solar heating; multi-objective optimization; decision making

\section{Introduction}

The share of Renewable Energy Sources (RES) in energy systems is growing rapidly to accelerate the energy transition and tackle climate change. However, their penetration in the heating and cooling sector, which accounts for more than 50\% of the final energy demand in EU [1], is only about 22\% in Europe [2]. One of the key solutions to increase this share on the short term and in a cost-effective way is to integrate renewable energy in existing District Heating $(\mathrm{DH})$ systems. Many initiatives are currently taken to do so. According to IRENA [3], Denmark has the ambition to increase the share of RES in their DH systems up to $73 \%$ in 2030 (vs. 42\% in 2014). China targets a $24 \%$ share by 2030.

In terms of renewable resources, biomass, solar heating and geothermal energy are the options with largest potential to reach higher shares of RES in DH's [3], also at large scale [4-6]. Among these options, solar collectors present the additional challenge of being an intermittent source of energy, therefore potentially requiring additional heat storage, which represents an interesting optimization problem. 
Hot water Thermal Energy Storage (TES) can provide load shifting and is 100 times cheaper than electricity storage for the same energy capacity [7]. Thanks to TES, up to $25 \%$ RES would be integrated in energy systems without significantly affecting its efficiency [8]. Hybrid systems composed of Combined Heat and Power (CHP) units integrated with RES and TES is therefore considered as a first step towards the 4th generation district heating systems [8].

TES alone can also be added to existing CHP's. It contributes to peak load shaving, it can store energy when the demand is low and deliver it when the demand is high. With an optimal operation, it can also increase the energy efficiency, which in turn results in lower $\mathrm{CO}_{2}$ emissions [9]. In many studies, the optimization of a combined CHP-TES system often focuses on economic aspects, taking into account the cost of $\mathrm{CO}_{2}$ emissions. Benalcazar [10] proposed an optimization method based on the economic performance for the optimal sizing of how water TES, integrated in an existing CHP plant considering specific investment cost and different carbon prices. His analysis showed that the integration of the TES units can save operational cost and decrease the use of the heat-only boiler, which reduces fuel consumption and decreases $\mathrm{CO}_{2}$ emissions. Mugnini et al. [11] assessed possible energy flexibility strategies to improve the performance of such system. Their results revealed that a hot water tank can increase the $\mathrm{CHP}$ working hours and primary energy savings. Lai et al. [12] developed an operation optimization model based on Particle swarm optimization method, to investigate the flexibility and thermodynamic performance of a CHP unit integrated with an integrated heat storage tank. Their results show that such an integration led to an increased range of operational conditions of CHP units.

Although the addition of Solar Thermal Collectors (STC) can lead to larger $\mathrm{CO}_{2}$ emission savings than TES alone, they generally increase the production costs of existing systems [3]. The question of the optimal combination of STC and TES in terms of both economic and environmental impacts may therefore be raised. This corresponds to a multiobjective optimization problem with two design variables, i.e., the sizes of the STC and the TES systems.

Single economic objective optimization does not provide alternative solutions to deal with conflicting objectives [13]. Therefore, recent research efforts focused on multi-objective optimization of energy systems. Multi-objective optimization is used to find a trade-off between two or more conflicting objectives to support decision making. Ren et al. [14] proposed a multi-objective linear programming method for operational strategy of a Distributed Energy System (DES). Their model was based on trade-off analysis of economic and environmental optimization. Fazlollahi et al. [15] developed a multi-objective, multi-period optimization for sizing and operating a DH system with the objectives of maximizing the system efficiency and minimizing the $\mathrm{CO}_{2}$ emissions and the Annual Total Cost (ATC), the annualized value of the total cost over the lifetime of the project. Luo et al. [16] developed a framework for the optimization of DES integrated with Genetic Algorithm for multi-objective optimization, and multi-criteria evaluated by Technique for Order Performance by Similarity to an Ideal Solution (TOPSIS) method. Karmellos et al. [17] presented a multi-objective Mixed-integer linear programming (MILP) model for the optimal design and operation of DES by $\varepsilon$-constraint method, with minimizing the ATC, and the total carbon emission as objective function. Franco and Versace [18] carried out a multi-objective strategy considering energetic and economic objectives to investigate design and operation strategy of a CHP-TES to DH network.

As discussed above, various approaches have therefore been applied to determine the economically and/or environmentally optimal design and operation of RES and TES integrated into existing CHP systems. However, the proposed methodologies can be further improved in the following respects. First, the modelling of the CHP systems could be more accurate. An increased accuracy of the techno-economic models for the following aspects could lead to more accurate results [19]: Piece-wise Linear Investment functions allowing for a non-linear evolution of the investment costs, and account for part-load efficiencies, start-up costs, CHP acceptable operation ranges and maximum 
ramp rates, which significantly affect technical and economic performances. Secondly, few recent works $[15,16]$ integrated multi-objective optimization models with decision making methods to optimize the capacity and the operation strategy of TES and RES integrated to existing CHP systems. Moreover, limited research was carried out on the effect of fluctuating investment cost on the sizing and the operation of the system.

In this work, we therefore aim at integrating multi-objective optimization and decisionmaking methods featuring advanced techno-economic models, and to apply them to 1 the STC and TES systems.

Our main objectives are the development a comprehensive methodology to allow decision-makers to determine the optimal design of hybrid heat and power production systems and to assess the economic and environmental impact of the optimal integration of STC and TES systems into existing, conventional CHP systems.

The main innovative features of this work can be summarized as follows:

- The techno-economic models of the sub-systems features Piece-Wise Linear Investment function, part-load efficiencies, start-up costs, maximum ramp rates and CHP acceptable operation ranges.

- The variation of the economic and technical parameters, such as ambient temperature, electricity and fuel prices, is considered.

- Pareto-optimal solutions are generated using multi-objective optimization, from which the optimal solution is picked using the TOPSIS-entropy method, an effective method to make decisions processes more reliable and accurate.

The paper is organized as follows. Section 2 describes the proposed methodologies. The case of a hybrid energy system is defined in Section 3, including the input data and the investigated scenarios. Section 4 presents and discusses the results of the case study. Lastly, conclusions are drawn in Section 5.

\section{Materials and Methods}

This Section describes the proposed methodology for the optimization of the studied hybrid systems. Their general structure is defined in Section 2.1. The multi-objective optimization model is then described in Section 2.2. Finally, the Decision-making method is presented in Section 2.3.

Figure 1 illustrates the flow chart of the optimization framework used in this study. The framework consists of three stages:

1. Pareto-optimal solutions, generated by multi objective optimization model. It involves a trade-off analysis between economic and environmental aspects.

2. Optimal solution selected among the Pareto solutions using a decision-making tool. The optimal solution with the maximum relative quality ranking is picked up as the final optimal solution.

3. Final design and operation strategy. The hourly operation strategy of the optimal solution is further described to assess performance of each unit with optimal capacity. More detailed description will be introduced in the Section 2.2.

\subsection{Hybrid Heat and Power Production System}

The components of the existing CHP system considered in this study are a $12 \mathrm{MW}_{\text {th }}$ coal-fired CHP with Extraction Condensing (EC) steam turbine, and two gas-fired Heat Only Boilers (HOB) with a thermal power of $5 \mathrm{MW}_{\text {th }}$, respectively, also connected to the system. The sizes of the STC and of the TES that will be added to the existing system are the design variables. A schematic of the system is given in Figure 2. Electricity is produced by the CHP and sold to the local market. The generated heat can be sent to both the heat clients and the TES system. HOBs are only in operation when the heat production is insufficient. The constraints related to each unit described in Section 2.2.2, and the input data described in Section 3.1. 

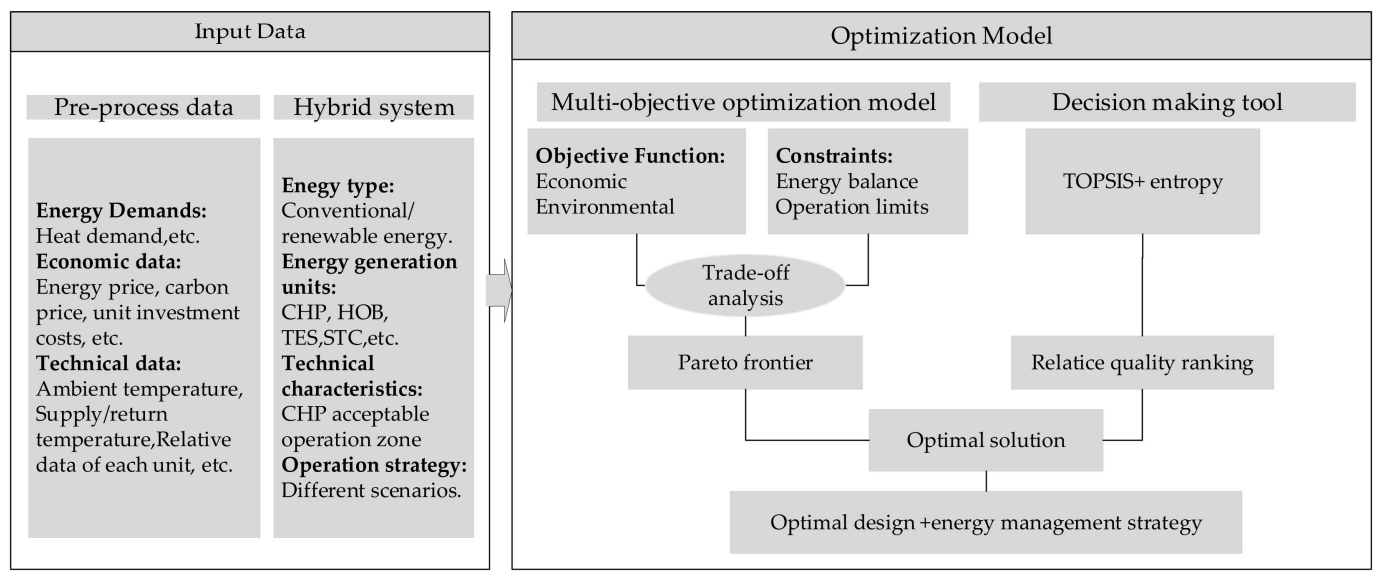

Figure 1. Optimization Framework of hybrid energy system.

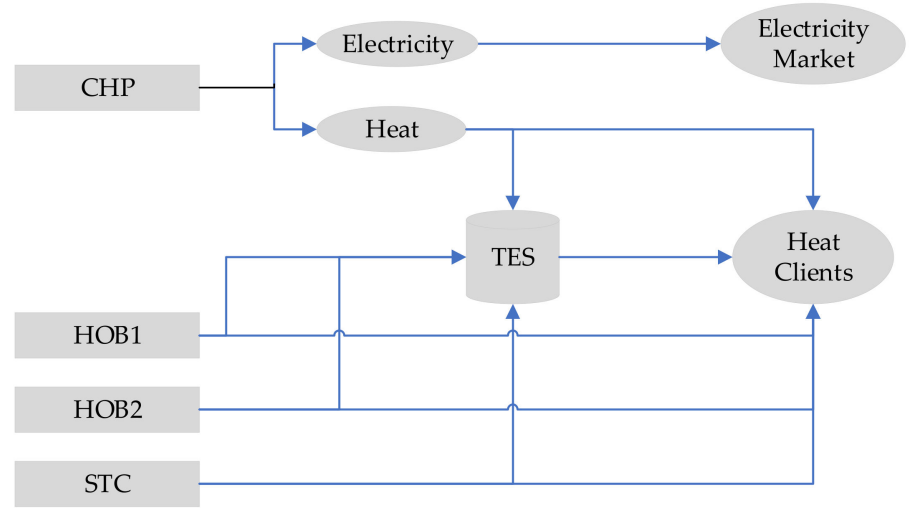

Figure 2. Schematic of Hybrid energy system.

\subsection{Optimization Model}

\subsubsection{Objective Function}

In this study, the weighting method [20] will be used to solve the multi-objective optimization problem through MILP method. The two objective functions to be minimized are the ATC and the total carbon emissions. A general objective function is then defined as shown in Equation (1):

$$
\min \left\{F_{o b j}=\alpha \cdot \frac{A T C}{A T C_{\min }}+(1-\alpha) \cdot \frac{\text { Carbon }}{\text { Carbon }_{\min }}\right\}
$$

where $\alpha$ is a weighting factor and where the objectives functions are normalized using the corresponding single optimization value $A T C_{\text {min }}$ and $C_{\text {arbon }}$ min .

The ATC of the studied hybrid systems is defined in Equation (2) as the sum of the annualized investment $\operatorname{cost} C_{i n v}$, the maintenance $\operatorname{cost} C_{M}$ and the operating $\operatorname{cost} C_{O}$, minus the revenues $\mathrm{R}_{S}$ from the electricity production [14]. The total $\mathrm{CO}_{2}$ emissions are calculated for all heat and power generation systems by multiplying the fuel consumption with the corresponding $\mathrm{CO}_{2}$ emission factor, as shown in Equation (3).

$$
\begin{gathered}
A T C=C_{i n v}+C_{M}+C_{O}-R_{S} \\
\text { Carbon }=\sum_{u} \sum_{t} C F_{u} * F C_{u, t}
\end{gathered}
$$

The total investment cost $C_{i n v}$ is calculated following Equation (4). The annualized investment cost $c_{u, t}^{i n v}, c_{t}^{\text {invTES }}$ and $c_{t}^{\text {invSTC }}$ (Equations (5)-(7)) are calculated using the annuity factor defined in Equation (8), which considers the discount rate $i$ and the lifetime $n_{u}$ for each unit, respectively. The maintenance costs are defined as a fixed proportion of 
the investment costs and are calculated following the same structures, see Equation (9). Operational costs consist of fuel consumption and unit startup costs, see Equation (10).

$$
\begin{gathered}
C_{i n v}=\sum_{u} \sum_{t}\left(c_{u, t}^{i n v} * \operatorname{Cap}_{u}+c_{t}^{i n v T E S} * V+c_{t}^{i n v S T C} * A\right) \\
c_{u, t}^{i n v}=\frac{a_{u} * I_{u}^{i n v}}{8760} \\
c_{t}^{i n v T E S}=\frac{a_{u} * I^{i n v T E S}}{8760} \\
c_{t}^{i n v S T C}=\frac{a_{u} * I^{i n v S T C}}{8760} \\
a_{u}=\frac{i *(1+i)^{n_{u}}}{(1+i)^{n_{u}}-1}, \forall \mathbf{u} \in \text { units, } \mathbf{t} \in \text { periods } \\
C_{M}=\sum_{u} \sum_{t}\left(c_{u, t}^{M} * C a p_{u}+c_{t}^{M T E S} * V+c_{t}^{M S T C} * A\right) \\
C_{O}=\sum_{u} \sum_{t}\left(c_{u, t}^{f u e l} * F C_{u, t}+\delta_{u, t} * S C_{u}\right)
\end{gathered}
$$

The revenues $R_{S}$ consist in selling electricity to the grid, see Equation (11).

$$
R_{S}=\sum_{t} P * E l_{t}
$$

\subsubsection{Constraints for System Design and Operation}

All units are subject to some constraints. The following constraints are considered in this study for the design and the operation of each sub-system.

\section{Common Types of Constraints}

Common types of constraints are applied to all units:

- Minimum and maximum loads

For all units, the production must be within the minimum and maximum loads, see Equation (12):

$$
P L R_{u, t}^{l b} * Q_{u}^{n o r m} \leq Q_{u, t} \leq P L R_{u, t}^{u b} * Q_{u}^{n o r m} \forall \mathbf{u} \in \text { units, } \mathrm{t} \in \text { periods }
$$

- $\quad$ Ramping rate limits

Maximum ramping rates (up and down) of the thermal units should be defined for stability, integrity and safety reasons, see Equation (13) and (14):

$$
\begin{gathered}
Q_{u, t+1}-Q_{u, t} \leq \operatorname{ramp}_{u p_{u, t}} * Q_{u}^{n o r m} \forall \mathbf{u} \in \text { units, } \mathrm{t} \in \text { periods } \\
Q_{u, t+1}-Q_{u, t} \leq \operatorname{ramp}_{\text {down }_{u, t}} * Q_{u}^{n o r m} \forall \mathbf{u} \in \text { units, } \mathrm{t} \in \text { periods }
\end{gathered}
$$

- State of units

In the framework of MILP optimization, the binary variable $I_{u, t}^{u s e}$ is used to illustrate the state of the units. It is constrained by the variables $T_{u, t}^{O N}$ and $T_{u, t}^{O F F}$ defining whether the unit is on or off at time $t$, see Equations (15) and (16).

$$
\begin{gathered}
I_{u, t+1}^{u s e}-I_{u, t}^{u s e} \leq T_{u, t+1}^{O N} \forall \mathrm{u} \in \text { units, } \mathrm{t} \in \text { periods } \\
I_{u, t}^{u s e}-I_{u, t+1}^{u s e}+T_{u, t+1}^{O N} \leq T_{u, t+1}^{O F F} \forall \mathrm{u} \in \text { units, } \mathrm{t} \in \text { periods }
\end{gathered}
$$

- Minimum uptime and downtime 
Minimum uptime and downtime constraints are considered for safety and reliability reasons. If a unit is in service, the duration should be at least equal to the defined minimum uptime, as indicated in Equation (17). Similarly, if a unit is not in running, the period should be at least equal to the defined minimum downtime as expressed in Equation (18).

$$
\begin{gathered}
\sum_{t-\text { min_uptime }}^{t} T_{u, t}^{O N} \leq I_{u, t}^{u s e} \forall \mathrm{u} \in \text { units, } \mathrm{t} \in(\text { min_uptime, periods }), \\
\sum_{t-\text { min_downtime }}^{t} T_{u, t}^{O F F} \leq 1-I_{u, t}^{u s e} \forall \mathrm{u} \in \text { units, } \mathrm{t} \in \text { (min_downtime, periods), }
\end{gathered}
$$

\section{Extraction Condensation CHP Unit}

The CHP plant considered in this study is of the Extraction Condensation type (EC): heat is provided to the heat clients through the condensation of steam extracted from the turbine. EC-based CHP can be operated in a flexible way, since steam can usually be extracted from more than one pressure stage, and power may vary with same heat production. In this study, the total energy efficiency of the CHP plant is considered as constant, as suggested in $[17,19]$.

For EC-based CHP's, the power loss coefficient $\beta$, defined as the power generation reduction caused by heat extraction, is a key characteristic [21]. It can be calculated based on the ambient and DH temperatures [22], see Equations (19) and (20):

$$
\begin{gathered}
\beta=1-\frac{T_{0}}{T_{M}} \\
T_{M}=\frac{T^{\text {supply }}-T^{\text {return }}}{\ln \left(\frac{T^{\text {supply }}}{T^{\text {return }}}\right)}
\end{gathered}
$$

The acceptable operation zone of the CHP plant in terms of heat extraction and electrical power for a given supply and return temperature is illustrated in Figure 3. It is elaborated as suggested by [22]. The blue line BC is the backpressure line, exhibiting a slope $\sigma$. It represents the operation points with the designed power to heat ratio [21]. The maximum load line $C D$ is parallel to the minimum load line AB (both with a slope $\beta$ ). Any line with the same slope corresponds to a constant fuel consumption.

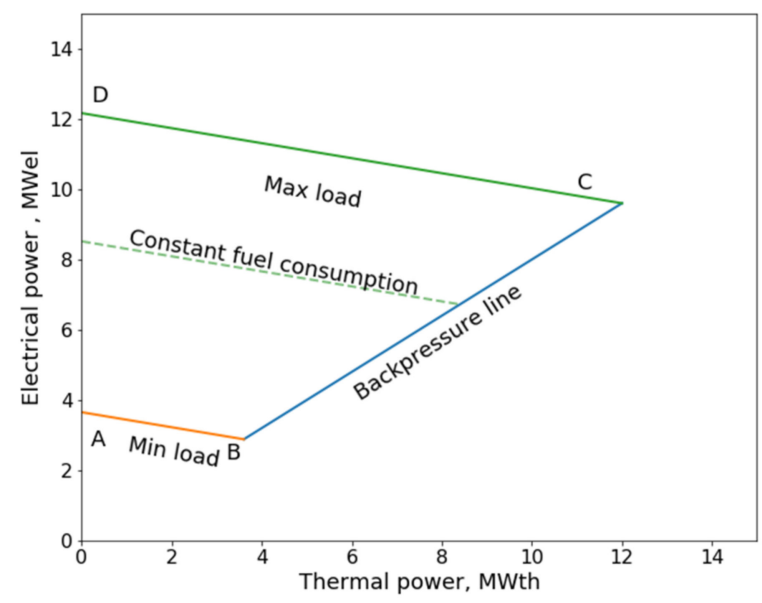

Figure 3. Cogeneration of Power and heat extraction for EC based CHP plant. 
Equation (21) and (22) express the corresponding constraints on the operational loads. The fuel consumption can be calculated using Equation (23).

$$
\begin{gathered}
P_{t}^{E C}=P L R_{t}^{E C} * I_{E C, t}^{u s e} *\left(\sigma^{E C}+\beta_{t}\right) * Q_{E C}^{n o r m}-Q_{t}^{E C} * \beta_{t} \forall \mathrm{t} \in \text { periods } \\
P_{t}^{E C} \geq \sigma^{E C} * Q_{t}^{E C} \forall \mathrm{t} \in \text { periods } \\
F C_{t}^{E C}=\left(Q_{t}^{E C}+P_{t}^{E C}\right) / \eta_{E C} \forall \mathbf{t} \in \text { periods }
\end{gathered}
$$

\section{Heat Only Boiler}

The part load efficiency of the gas-fired Heat Only Boiler (HOB) is considered according to the model proposed by [19]. Equation (24) provides an expression for the consumption of the HOB boiler, which leads to the non-linear evolution of its efficiency, as shown in Figure 4.

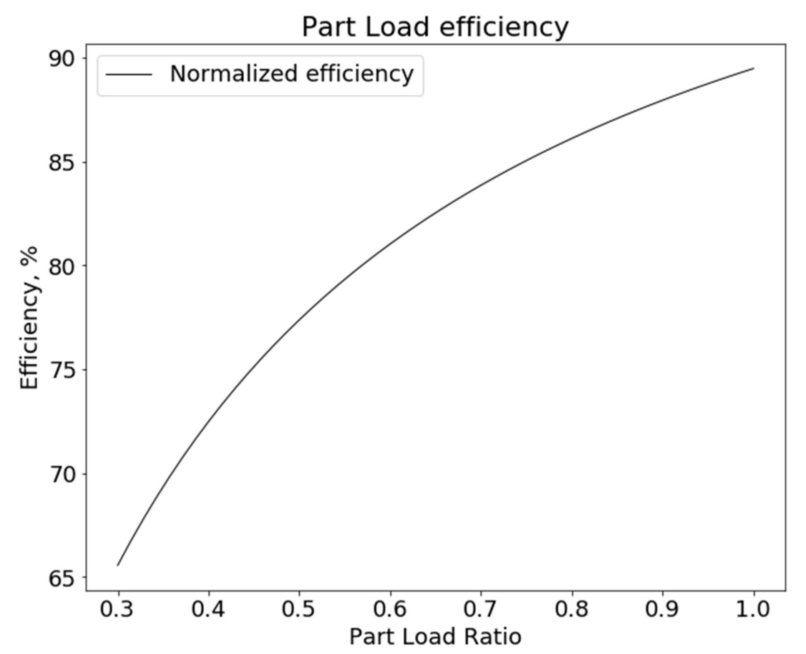

Figure 4. Normalized efficiency for $\mathrm{HOB}$, according to [19].

$$
F C_{t}^{H O B}=0.4576 * Q_{H O B}^{n o r m} * I_{H O B, t}^{u s e}+0.6599 * Q_{t}^{H O B} \forall \mathrm{t} \in \text { periods }
$$

Equations (25) and (26) state that the two HOB (HOB1 and HOB2) are only in operation when the heat demand cannot be satisfied by the main steam boiler (peak load), during maintenance or when the demand exceeds the CHP output.

$$
\begin{gathered}
Q_{t}^{E C} \geq I_{H O B 1, t}^{u s e} * Q_{C H P}^{\text {norm }} \\
Q_{t}^{E C}+Q_{t}^{H O B} \geq I_{H O B 2, t}^{u s e} *\left(Q_{C H P}^{n o r m}+Q_{H O B}^{\text {norm }}\right)
\end{gathered}
$$

Thermal Energy Storage Unit

The Thermal Energy Storage (TES) system is modeled based on the formulation proposed by Wang et al. [23]. Upper and lower boundary conditions are defined for the charging and discharging rates, see Equations (27) and (28). To ensure the availability of the TES, the stored thermal energy at the end of the schedule period is assumed to be equal to its initial value, see Equation (29). The energy balance of the system, taking into account the storage efficiency and the charging and discharging efficiencies, is expressed in Equation (30). The binary variable $z(t)$ is used to illustrate the TES charging and discharging operation status, see Equation (31). Equations (32) and (33) express the constraints that the stored thermal energy must be lower than the maximum storage capacity of the system, which depends on TES volume and DH supply and return temperatures.

$$
0 \leq H S_{t}^{c h r} \leq \alpha_{t}^{c h r} \cdot \text { Cap }_{t}^{\text {TES }} \forall \mathrm{t} \in \text { periods }
$$




$$
\begin{gathered}
0 \leq H S_{t}^{d i s} \leq \alpha_{t}^{d i s} \cdot C_{t}{ }^{T E S} \forall \mathrm{t} \in \text { periods } \\
Q_{1}^{T E S}=Q_{\text {end }}^{T E S} \forall \mathrm{t} \in \text { periods } \\
Q_{t}^{T E S}=\eta_{s}^{T E S} Q_{t-1}^{T E S}+\eta_{c h r}^{T E S} H S_{t}^{c h r}-H S_{t}^{d i s} / \eta_{\text {dis }}^{T E S} \forall \mathrm{t} \in \text { periods } \\
z(t)=\left\{\begin{array}{ll}
1, & H S_{t}^{d i s}=0 \\
0, & H S_{t}^{c h r}=0
\end{array} \forall \mathrm{t} \in\right. \text { periods } \\
\operatorname{Cap}_{t}^{T E S}=\frac{\rho V c}{3600}\left\{\min \left(\left(T_{t}^{\text {supply }}-5\right), 98\right)-\left(T_{t}^{\text {return }}+5\right)\right\} \forall \mathbf{t} \in \text { periods } \\
Q_{t}^{T E S} \leq \text { Cap } p_{t}^{T E S} \forall \mathbf{t} \in \text { periods }
\end{gathered}
$$

The investment costs for the TES system, including the auxiliary equipment, can be estimated following [10,24]. Due to limitation of linear programming method, the exponential decay function of specific investment cost should be replaced with piecewise linear approximation for further use [10]. The specific investment costs curve according to [24], a piecewise linear function is used to make it compatible with MILP, see in Figure 5.

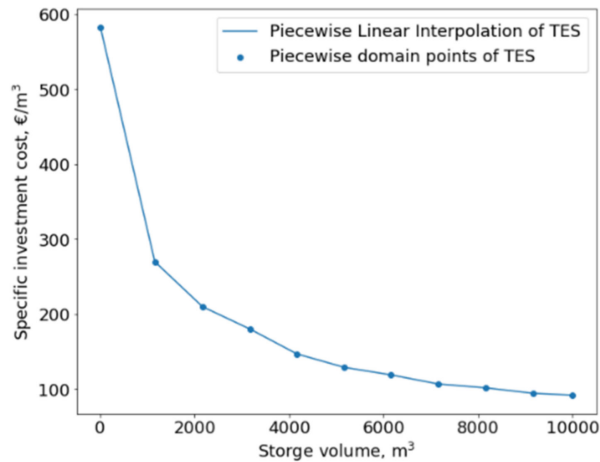

(a)

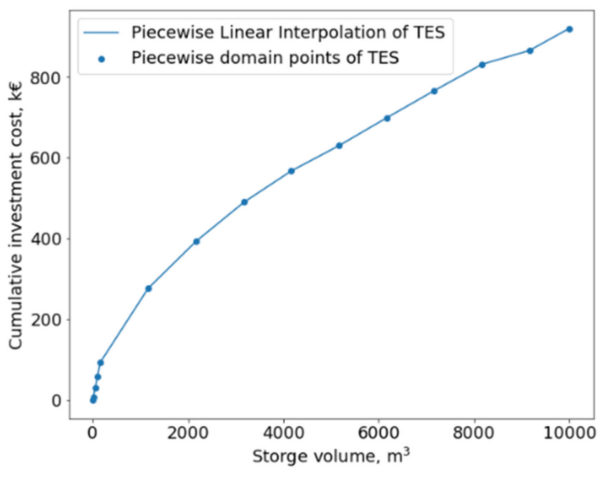

(b)

Figure 5. Investment costs for TES systems: (a) Specific investment cost according to [24]; (b) Cumulative investment cost.

\section{Solar Thermal Collectors Unit}

Equations (34) shows how the heating performance of STC can be calculated based on the collector area, solar irradiance and DHN temperature according to the formulation from [25].

$$
\begin{aligned}
Q_{t}^{S T C}= & A *\left(\left(0.839 * Q_{t}^{S R}-2.46 *\left(T_{t}^{\text {aver }}-T_{t}^{\text {ambient }}\right)\right.\right. \\
& \left.-0.0197 *\left(T_{t}^{\text {aver }}-T_{t}^{\text {ambient }}\right)^{2}\right) \forall \mathbf{t} \in \text { periods }
\end{aligned}
$$

The specific investment costs of ground mounted solar collector field (shown in Figure 6a) are estimated based on [25]. PLI is also applied, cumulative investment cost see Figure $6 b$.

\section{Energy Balance}

Equation (35) expresses that the heat demand from the local distribution network must always be fulfilled for each time interval.

$$
Q_{t}^{C H P}+Q_{t}^{H O B}+Q_{t}^{S T C}+\eta_{d i s}^{T E S} H S_{t}^{\text {dis }}-H S_{t}^{c h r} \geq Q_{t}^{\text {demand }} \forall \mathrm{t} \in \text { periods }
$$




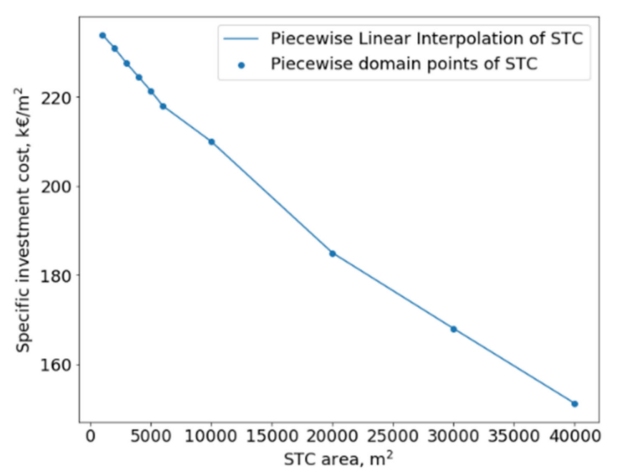

(a)

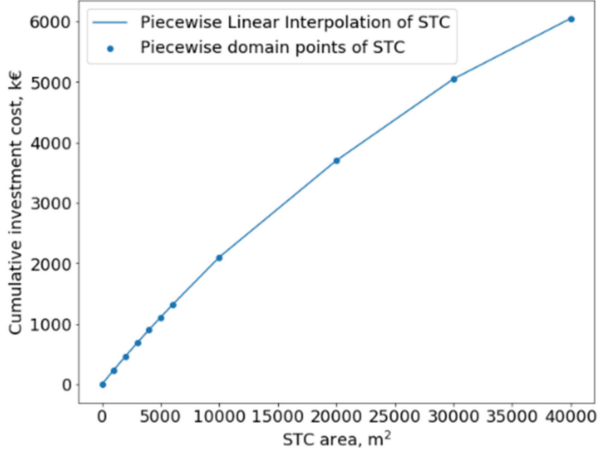

(b)

Figure 6. Investment costs for STC: (a) Specific investment cost according to [25]; (b) Cumulative investment cost.

\subsection{Decision-Making Method}

Figure 7 illustrates the flow chart of the decision-making process used in this study. The decision-making process is to provide a quantitative evaluation on the system with several conflicting objectives, to support the Decision makers the most potential solutions by considering the important criteria [13]. To evaluate performance of the multi-objective optimization model, a decision-making method combining Technique for Order Preference by Similarity to Ideal Solution (TOPSIS) with Entropy method (EM) is investigated. TOPSIS is a classic method to find optimal solution within finite objectives [26], while EM aims at determining the weights of each objective in an automatic way, in order to minimize man-made error [27]. As illustrated in Figure 7, The TOPSIS-entropy method selects the solution with the maximal relative quality as the optimal solution.

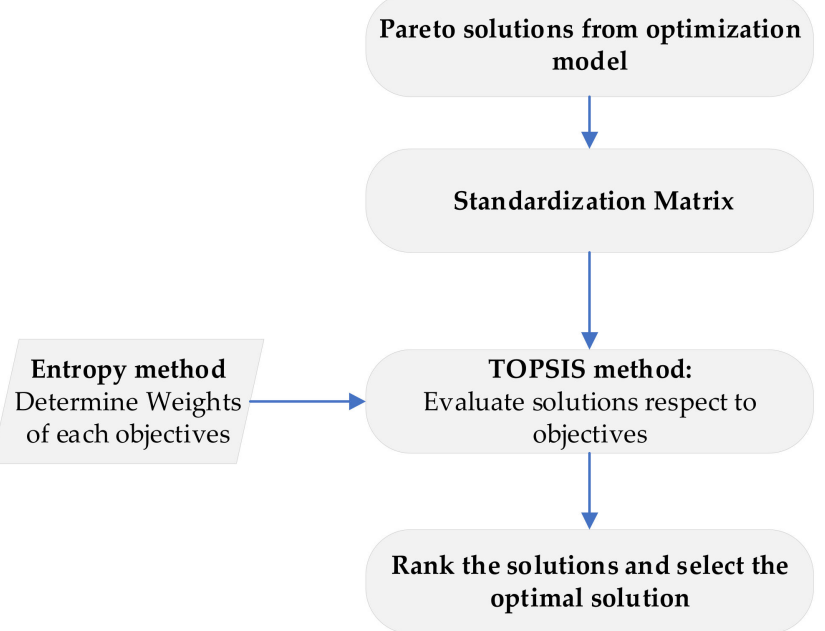

Figure 7. Flowchart of Decision-making process.

The different steps followed to the TOPSIS-entropy method are as follows [28]:

- Weights calculation:

The first step is matrix normalization, see Equation (36). This ensures that all indicators are positive and present comparable ranges. Then, standardized value $p_{i j}$ and entropy value of objective $e_{j}$ are calculated using Equations (37) and (38). Finally, weighting values of the objectives $\omega_{j}$ are defined, see Equation (39).

$$
y_{i j}=\frac{\max \left(x_{i j}\right)-x_{i j}}{\max \left(x_{i j}\right)-\min \left(x_{i j}\right)} \forall \mathrm{i} \in[1 \ldots m], \mathrm{i} \in(1 \ldots \mathrm{n})
$$




$$
\begin{gathered}
p_{i j}=\frac{y_{i j}}{\sqrt{\sum_{i=1}^{m} y_{i j}}} \forall \mathrm{i} \in[1 \ldots m], \mathrm{i} \in(1 \ldots \mathrm{n}) \\
e_{j}=-\frac{1}{\ln (m)} \sum_{i=1}^{m} p_{i j} \ln \left(p_{i j}\right) \forall \mathrm{j} \in(1 \ldots \mathrm{n}) \\
\omega_{j}=\frac{1-e_{j}}{\sum_{j=1}^{n}\left(1-e_{j}\right)}
\end{gathered}
$$

- $\quad$ TOPSIS method

The weighted matrix used as a basis for the TOPSIS method is described in. Equation (40) The positive ideal solution $V^{+}$and negative ideal solution $V^{-}$are then determined using Equations (41) and (42). The distances $D^{+}$and $D^{-}$between any evaluated result and the two positive and negative solution $V^{+}$and $V^{-}$are calculated using Equations (43) and (44). Finally, the relative quality $C_{i}$ is defined to compare the distance between any result and the two ideal solutions, see Equation (45). The optimal solution corresponds to the highest value of $C_{i}$.

$$
\begin{gathered}
v_{i j}=\omega_{i j} * y_{i j} \forall \mathrm{i} \in[1 \ldots \mathrm{m}], \mathrm{i} \in(1 \ldots \mathrm{n}) \\
V^{+}=\left\{\left(\max V_{i j} \mid \mathrm{j} \in J_{1}\right),\left(\min V_{i j} \mid \mathrm{j} \in J_{2}\right)\right\} \forall \mathrm{i} \in(1 \ldots \mathrm{n}) \\
V^{-}=\left\{\left(\min V_{i j} \mid \mathrm{j} \in J_{1}\right),\left(\max V_{i j} \mid \mathrm{j} \in J_{2}\right)\right\} \forall \mathrm{i} \in(1 \ldots \mathrm{n}) \\
D^{+}=\sqrt{\sum_{j=1}^{n}\left(V_{i j}-V_{j}^{+}\right)^{2}} \forall \mathrm{i} \in(1 \ldots \mathrm{n}) \\
D^{-}=\sqrt{\sum_{j=1}^{n}\left(V_{i j}-V_{j}^{-}\right)^{2}} \forall \mathrm{i} \in(1 \ldots m) \\
C_{i}=\frac{D^{-}}{D^{+}-D^{-}} \forall \mathrm{i} \in(1 \ldots m)
\end{gathered}
$$

\section{Case Study}

In this Section, the proposed optimization framework is applied to a specific case of hybrid system described in Section 2.1. The considered input data is described in Section 3.1. Four different scenarios are defined in Section 3.2.

\subsection{Input Data}

The considered heat demand, ambient temperature, supply and return temperatures are field data retrieved in 2017 from an existing DH plant located in France. The hourly market electricity price was imported from EPEX SPOT for the year 2017 [29] and local climate data of solar radiation were retrieved from PVGIS for the same year [30]. The impact of the uncertainty on the main parameters will be investigated in Section 4.4.

However, the annual profile with 8760 time steps makes is difficult to solve due to complexity of optimization model [31-33]. To limit the computational time without significantly impacting the simulation results [32], the approach of typical periods is used in this work [33], a full year period was discretized into 12 typical days, each of them being representative for a month.

Figure 8 shows that the heat demand varies from $1.44 \mathrm{MW}_{\text {th }}$ to $16.9 \mathrm{MW}_{\text {th }}$. The average heat load and heat load variations are larger in the winter. The corresponding supply and return temperatures range from 75 to $90^{\circ} \mathrm{C}$ and from 55 to $75^{\circ} \mathrm{C}$, respectively. The average electricity price is also slightly higher in the winter, as illustrated in Figure 9. For each typical day, the heating load peak is observed between 8 and $10 \mathrm{AM}$ and between 8 and $10 \mathrm{PM}$, while the peak of electricity price is observed between 8 and $9 \mathrm{AM}$ and between 6 and $7 \mathrm{PM}$. The hourly variations of ambient temperature and solar irradiance are also presented in Figure 10. The heat collected by the STC was calculated following the methodology of Schmidt (Ref. [10]). The considered tilt angle of the collector was $40^{\circ}$. 


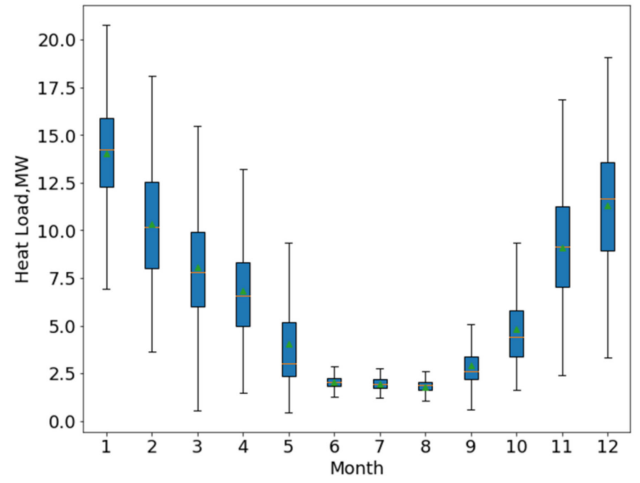

(a)

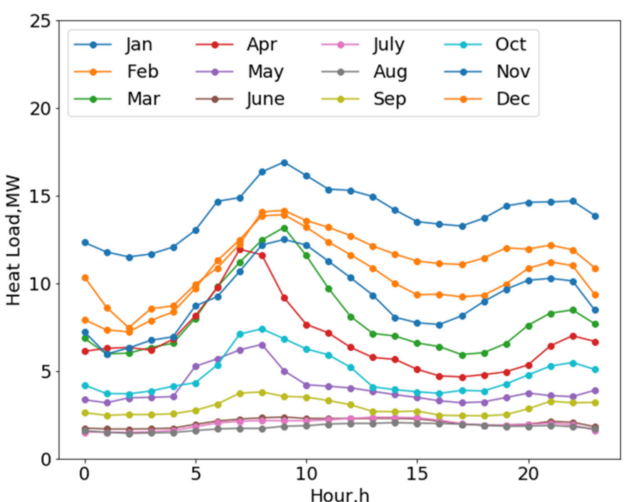

(b)

Figure 8. Heat Load in: (a) one year; (b) monthly typical days.

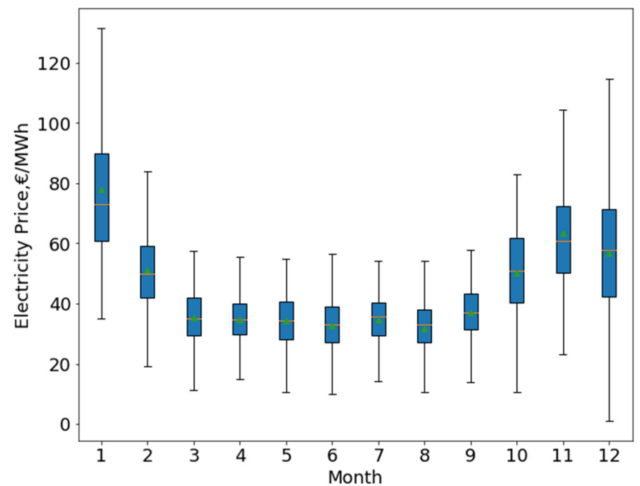

(a)

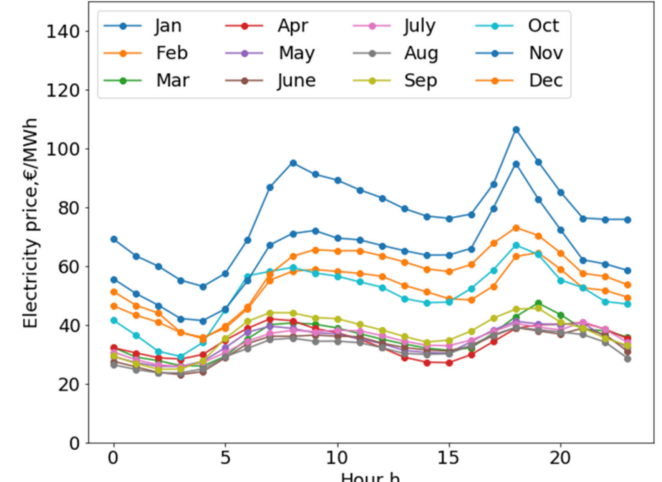

(b)

Figure 9. Electricity price in: (a) one year; (b) monthly typical days [29].

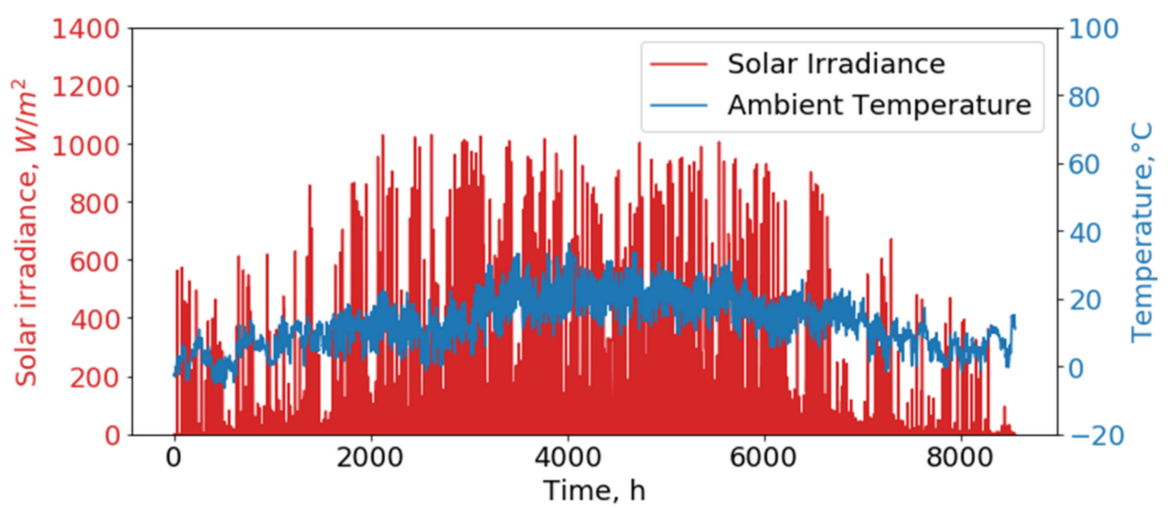

Figure 10. Hourly variation of ambient temperature and solar irradiance over the year [30].

The considered technical parameters of the heating and the thermal storage systems are provided in Tables 1 and 2. The related economic parameters, including investment and maintenance costs, lifetime and startup costs are presented in Table 3. The startup costs actually vary with the size of the units, but the constant values from [34] were considered here as they match the considered range of unit size.

$\mathrm{CO}_{2}$ emissions are calculated based on the specific emission factors to the primary consumption [1]: $350 \mathrm{~kg} \mathrm{CO} / \mathrm{MWh}$ for coal and $200 \mathrm{~kg} \mathrm{CO}_{2} / \mathrm{MWh}$ for natural gas [35]. The $\mathrm{CO}_{2}$ price in France in 2017 is collected from World Bank Carbon Pricing dashboard $30.5 €$ per tonne [36]. The fuel costs are assumed constant: $28 € /$ MWh for Coal and $32 € / \mathrm{MWh}$ for natural gas [34]. 
The following assumption were also made on the efficiency of the systems: the effect of incidence angle was neglected in the design of the STC system and the CHP operation efficiency was considered constant.

Table 1. Technical parameters of each unit.

\begin{tabular}{cccccccc}
\hline Units & Capacity & $\begin{array}{c}\text { Minimum Part } \\
\text { Load Ratio }\end{array}$ & Min Uptime & $\begin{array}{c}\text { Min } \\
\text { Downtime }\end{array}$ & $\begin{array}{c}\text { Ramp-Up } \\
\text { Rate \%/h }\end{array}$ & $\begin{array}{c}\text { Ramp-Down } \\
\text { Rate \%/h }\end{array}$ & $\begin{array}{c}\text { Norm } \\
\text { Efficiency }\end{array}$ \\
\hline CHP & $12 \mathrm{MW}$ & 0.3 & 10 & 7 & 30 & 30 & 0.883 \\
HOB1 & $5 \mathrm{MW}$ & 0.3 & 2 & 2 & 100 & 100 & 0.9 \\
HOB2 & $5 \mathrm{MW}$ & 0.3 & 2 & 2 & 100 & 100 & 0.9 \\
TES & $0-6000 \mathrm{~m}^{3}$ & 0 & 4 & 4 & 100 & 100 & - \\
STC & $0-40,000 \mathrm{~m}^{2}$ & 0 & 1 & 1 & 100 & 100 \\
\hline
\end{tabular}

Table 2. Technical parameters of TES [23].

\begin{tabular}{cccccc}
\hline Unit & $\begin{array}{c}\text { Charging } \\
\text { Ratio }\end{array}$ & $\begin{array}{c}\text { Discharging } \\
\text { Ratio }\end{array}$ & $\begin{array}{c}\text { Storage Efficiency } \\
\text { per Hour }\end{array}$ & $\begin{array}{c}\text { Charging } \\
\text { Efficiency }\end{array}$ & $\begin{array}{c}\text { Discharging } \\
\text { Efficiency }\end{array}$ \\
\hline TES & 0.4 & 0.4 & 0.998 & 0.95 & 0.95 \\
\hline
\end{tabular}

Table 3. Economic data of each unit [34].

\begin{tabular}{ccccc}
\hline Units & Investment Cost & Maintenance Cost & Startup Cost per Time & Lifetime \\
\hline CHP & $1154 € / \mathrm{kW}$ & $43.2 € /(\mathrm{kW} \cdot$ year $)$ & $5000 €$ & 25 \\
HOB & $62.9 € / \mathrm{kW}$ & $1.26 € /(\mathrm{kW} \cdot$ year $)$ & $1290 €$ & - \\
TES & See Figure 5 & - & - & 25 \\
STC & See Figure 6 & - & 30 \\
\hline
\end{tabular}

\subsection{Scenarios}

Different scenarios are investigated in this study to analyze the impact of the integration of TES and STC systems into the existing CHP system. Scenario 1 covers the operation of the existing system without the addition of TES nor STC. Both systems are then considered and optimized in Scenario 2. In Scenarios 3 and 4, the addition of TES or STC alone is studied. The scenarios are summarized in Table 4.

Table 4. Overview of each Scenario.

\begin{tabular}{cccccc}
\hline Scenario Name & CHP & HOB1 & HOB2 & TES & STC \\
\hline 1 & $\bullet$ & $\bullet$ & $\bullet$ & & \\
2 & $\bullet$ & $\bullet$ & $\bullet$ & $\bullet$ & $\bullet$ \\
3 & $\bullet$ & $\bullet$ & $\bullet$ & $\bullet$ \\
\hline
\end{tabular}

\section{Results and Discussion}

In this Section, the results of the optimization performed for the 4 Scenarios of the case study are presented and discussed. In this study, the MILP model implemented in Python and solved with IBM DOcplex toolbox. Section 4.1 gives the results of the Pareto Frontiers for all Scenarios. In Section 4.2, the optimal solutions chosen using the TOPSIS-entropy method are presented. Section 4.3 gives more detailed information on the hourly operation strategy, and Section 4.4 presents a sensitivity analysis on the main parameters.

\subsection{Pareto Frontiers}

Figure 11 shows the Pareto frontiers computed for Scenarios 2 to 4 in terms of ATC and $\mathrm{CO}_{2}$ emissions, expressed relatively to the reference Scenario 1 . In Scenario 1, the ATC is $4380 \mathrm{k} €$ /year and the $\mathrm{CO}_{2}$ emissions are 43,435 ton/year. 


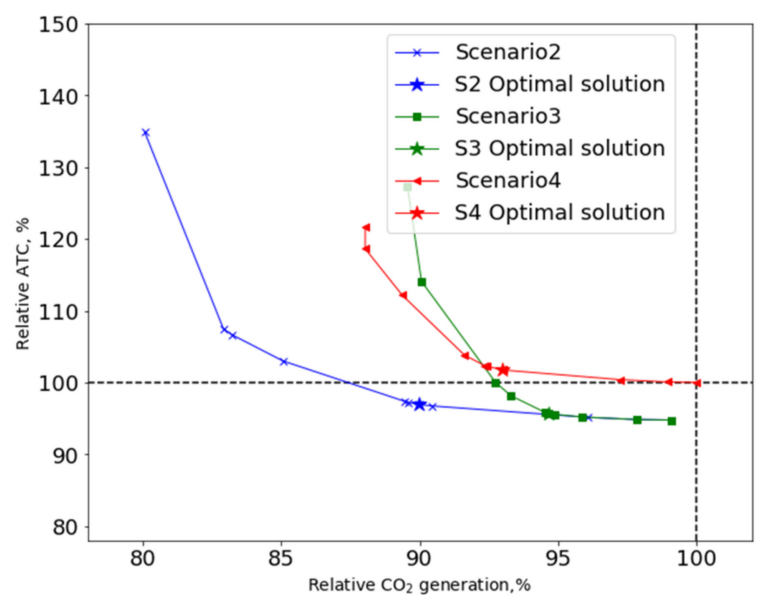

Figure 11. Relative Pareto frontiers for Scenarios relative to Scenario 1.

Considering the addition of TES only (Scenario 3) quickly allows for a reduction of the system cost (5\%) and a moderate reduction of the $\mathrm{CO}_{2}$ emissions (up to $1 \%$ less). This is due to the larger consumption of the produced heat hen heat storage is available (see Section 4.3). When even lower $\mathrm{CO}_{2}$ emissions must be reached with TES only, the price of the system however increases very sharp: it becomes higher than the reference cost for $\mathrm{CO}_{2}$ emissions reductions around $7 \%$ and increases exponentially afterwards: $+30 \%$ compared to the reference scenario for a $10 \% \mathrm{CO}_{2}$ emissions reduction.

On the other hand, considering STC only (Scenario 4) immediately leads to a higher cost, because of the higher price of STC. This system however becomes cheaper than TES only to reach $\mathrm{CO}_{2}$ emissions reductions larger than $8 \%$, although the cost also increases very rapidly for larger emission savings.

Figure 11 also shows that, combining TES and STC (Scenario 2) allows decreasing the ATC while reaching much larger $\mathrm{CO}_{2}$ emissions reduction. The combination of these systems indeed leads to the valorization of a higher amount of heat collected by the STC system by storing it and making it available when the demand is high. Parity with the reference scenario in terms of costs is reached for $12 \%$ less $\mathrm{CO}_{2}$ emissions. For even lower emissions, the cost increase is also significantly reduced compared to TES or STC only: $17 \%$ less $\mathrm{CO}_{2}$ is emitted for cost increase of $7 \%$. The installation of the additional equipment is made more cost-effective by their complementarity.

\subsection{TOPSIS-Entropy Method Analysis}

The TOPSIS-entropy method was used to choose the optimal solution on the Pareto frontiers obtained from the MILP optimizations. The weights calculated by the entropy method for each Scenario are very similar: around 0.54 and 0.46 for $A T C$ and $\mathrm{CO}_{2}$ emissions respectively. The solutions presenting the maximum relative quality for each Scenario are given in Table 5 and illustrated on the Pareto frontiers of Figure 11. The results generated for 12 representative days, see Section 3.1, have been extrapolated to a full year. Compared to the reference Scenario 1, the identified, optimal solution for Scenario 2 corresponds to a decrease of both the $\mathrm{CO}_{2}$ emissions $(10 \%)$ and the ATC (3\%), which is an excellent trade-off. The total efficiency of the system increases from $87 \%$ to $92 \%$, while the share of renewable energy in the system reaches $10 \%$. The optimal solution for TES only (Scenario 3) is selected before the strong increase of the system cost on the Pareto frontier. The $\mathrm{CO}_{2}$ emissions are reduced by $5 \%$ while the cost is reduced by $4 \%$. When only the STC system is installed (Scenario 4), the optimal solution is again selected before the strong increase of the cost. In that case, the cost increases with $2 \%$, for a $\mathrm{CO}_{2}$ emissions reduction of $7 \%$. The $A T C$ is higher than for Scenario 2 because of the lower proportion of renewable heat that can be consumed. The addition of TES indeed allows for the displacement of the consumption of the heat collected by the STC to the periods when the demand is higher. 
Table 5. Optimal solutions by TOPSIS-entropy method for each scenarios.

\begin{tabular}{|c|c|c|c|c|c|c|c|}
\hline $\begin{array}{l}\text { Scenario } \\
\text { Name }\end{array}$ & $\mathrm{TES} / \mathrm{m}^{3}$ & $\mathrm{STC} / \mathrm{m}^{2}$ & $\begin{array}{c}\mathrm{CO}_{2} \\
\text { (ton/year) }\end{array}$ & $\begin{array}{c}A T C \\
\text { (k€/year) }\end{array}$ & $\begin{array}{l}\text { HOB Operation } \\
\text { Hour (h/year) }\end{array}$ & $\begin{array}{c}\text { Total } \\
\text { Efficiency, \% }\end{array}$ & $\begin{array}{c}\text { Share of } \\
\text { RES, \% }\end{array}$ \\
\hline 1 & - & - & 43,435 & 4380 & 1520 & 87 & 0 \\
\hline 2 & 1382 & 22,399 & 39,268 & 4258 & 730 & 92 & 10 \\
\hline 3 & 742 & - & 41,184 & 4198 & 730 & 88 & 0 \\
\hline 4 & - & 17,649 & 40,363 & 4471 & 1460 & 90 & 7 \\
\hline
\end{tabular}

\subsection{Hourly Operation Strategy}

In this Section, the hourly operation of the optimal systems selected for the 4 scenarios during the typical days are presented and discussed. Figure 12 shows the hourly heat production per system and the hourly operation modes of the CHP on its operational map, over the 12 typical days in a row. It is obvious that integration of TES and STC significantly improve system operation flexibility and efficiency.

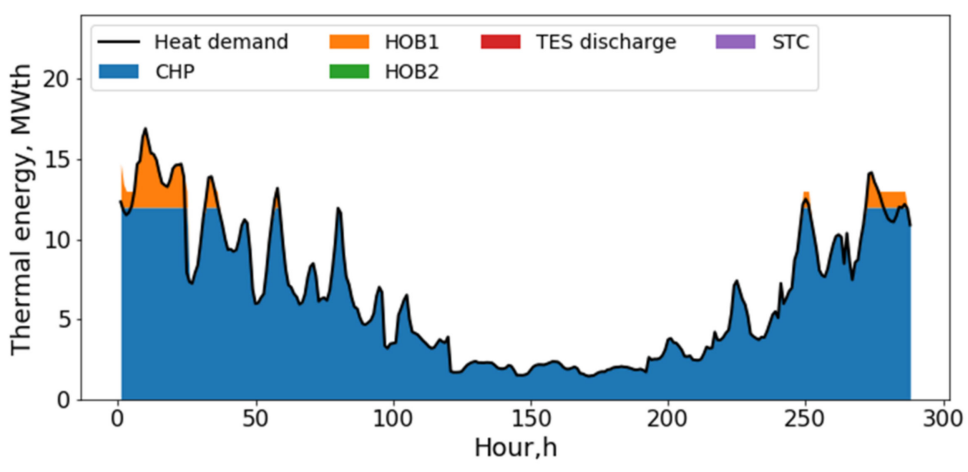

(a)

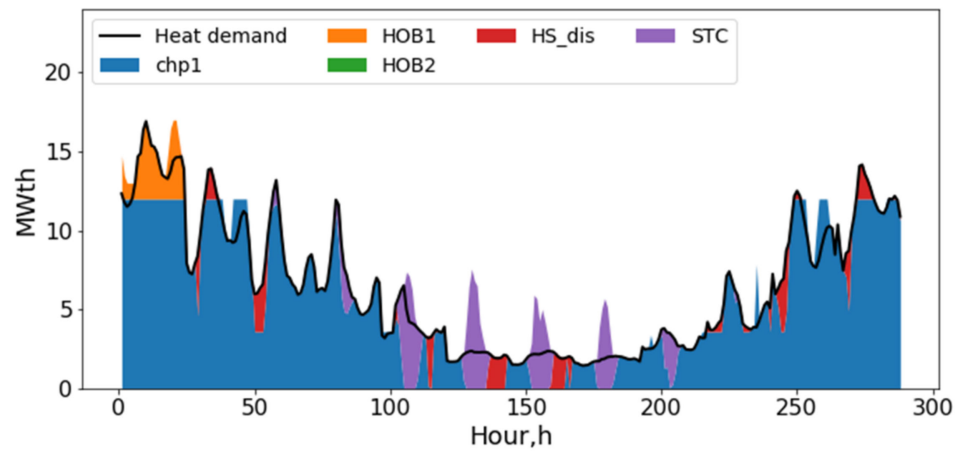

(c)

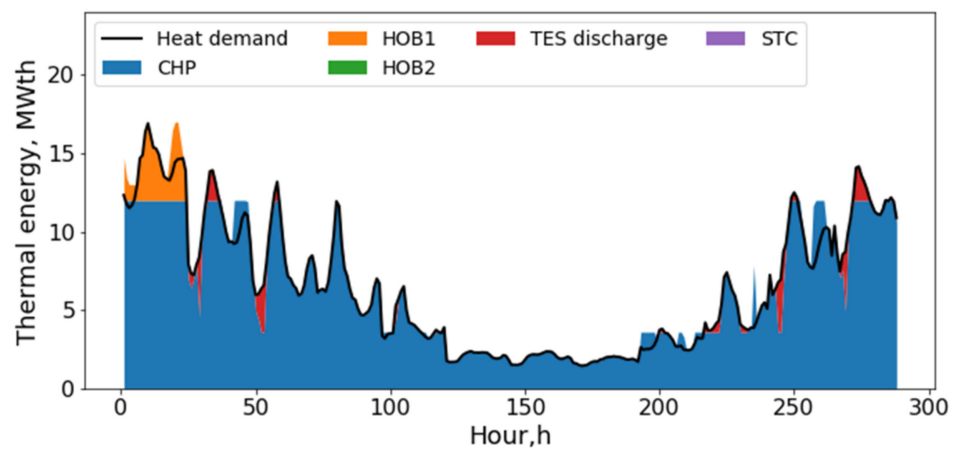

(e)

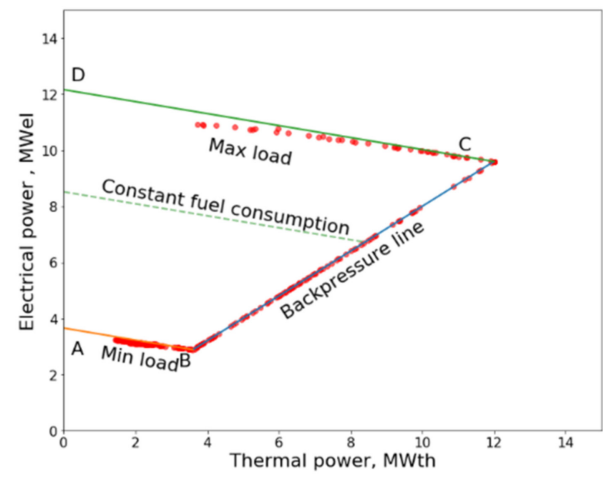

(b)

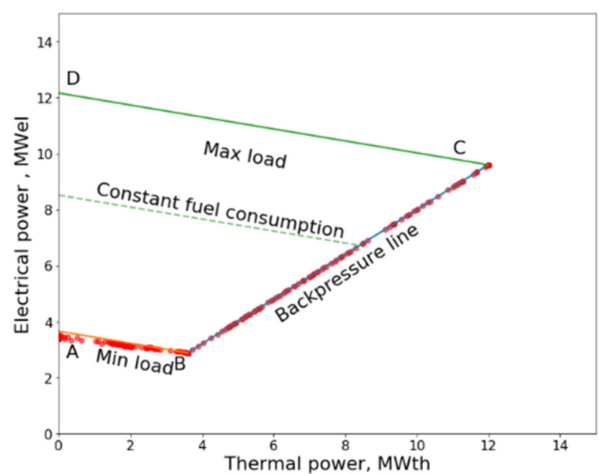

(d)

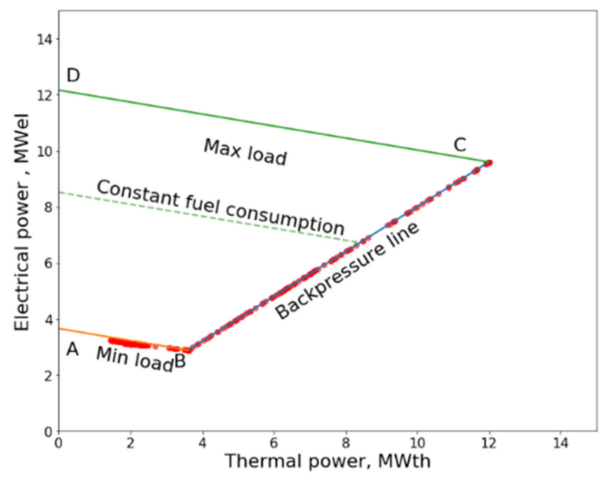

(f)

Figure 12. Cont. 


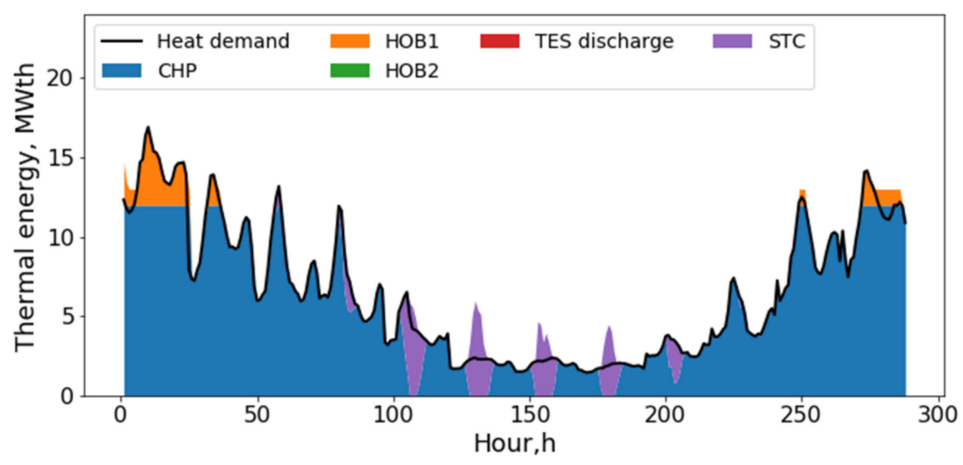

(g)

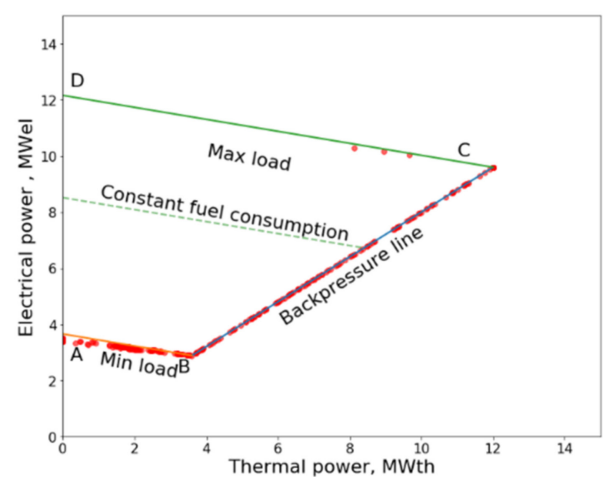

(h)

Figure 12. Hourly heat production for all Scenarios over the 12 typical days in a row: (a) Hourly Heat production of Scenario 1; (b) CHP operation field of Scenario 1; (c) Hourly Heat production of Scenario 2; (d) CHP operation field of Scenario 2; (e) Hourly Heat production of Scenario 3; (f) CHP operation field of Scenario 3; (g) Hourly Heat production of Scenario 4; (h) CHP operation field of Scenario 4.

First, it can be observed that the TES and the STC systems play an important role in increasing the system flexibility. The system with TES is more flexible as it can achieve peak load shaving and load valley filling, which results in a decrease of the HOB operation [10]. The HOB's are operated up to $52 \%$ less when TES is implemented (Scenarios 2 and 3), as shown in Table 5. In the winter period, the thermal energy supplied by HOB during peak load time in Scenarios 1 is replaced by TES in Scenarios 2 and 3. During the summer period, the daytime heat demand is covered by STC in Scenarios 2 and 4 . As expected, the excess heat produced by STC in Scenario 2 is stored in TES and discharged later on when STC cannot meet the demand.

Secondly, the operational flexibility of the CHP unit is also increased by the integration of TES and STC. Figure 12 shows that the CHP operates more on the left-hand part of the A-B line (minimum fuel consumption) in Scenario 2 than in Scenario 1, which helps increasing the electrical power generation for the same fuel consumption and, hence, the same $\mathrm{CO}_{2}$ emissions.

The detailed performances of the TES system are also shown in Figure 13. TES enables the operation of the system associated with electricity prices, to maximize the profits from selling electricity without affect heat supply safety. Furthermore, TES is more active in the summer period when used in combination with STC. The optimal TES size in Scenario 2 is therefore twice larger than for Scenario 3, see Table 5.

\subsection{Sensitive Analysis}

The input parameters used in the case study above are prone to uncertainty. To assess the impact of these uncertainties, a sensitivity analysis is carried out for the optimal solution of Scenario 2, for the following key input parameters [37]: heat demand, carbon price, electricity price, fuel price and interest rate.

Figure 14 shows the performance of the optimal solutions in terms of $A T C, \mathrm{CO}_{2}$ emissions and size of TES and STC, with the variation of the inputs $( \pm 20 \%)$. It must be noted that each of these results corresponds to an optimal solution computed for the new set of input parameters, and not to the results obtained for the reference optimal solution for other input parameters. 


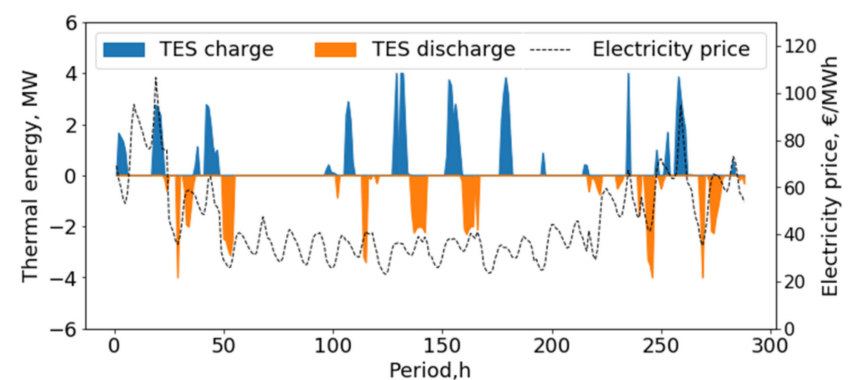

(a)

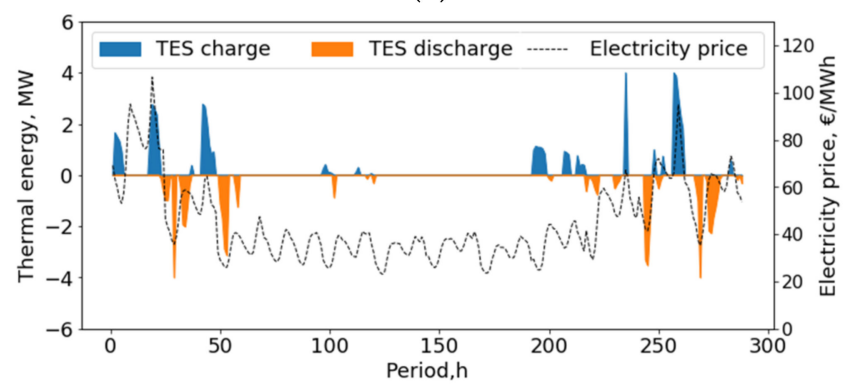

(c)

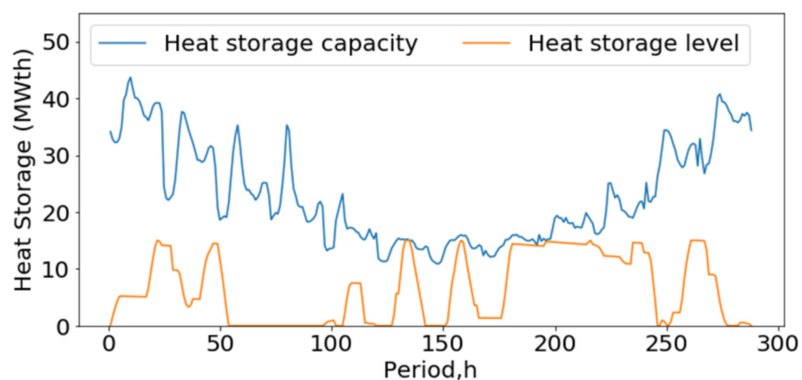

(b)

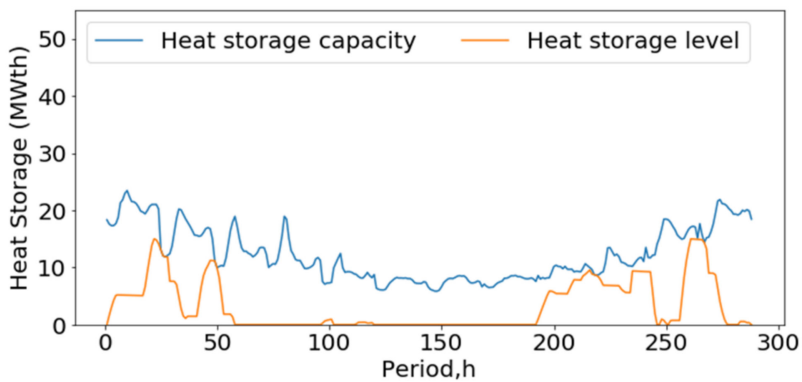

(d)

Figure 13. Charging or discharging load and heat storage levels of TES over the 12 typical days in a row: (a) TES charging and discharging load of Scenario 2; (b) TES heat storage levels of Scenario 2; (c) TES charging and discharging load of Scenario 3; (d) TES heat storage levels of Scenario 3.

Although they affect the optimal sizes of the TES and STC systems, the influence of economic parameters on the amount of $\mathrm{CO}_{2}$ emitted in the optimal cases is negligible compared to the influence of the heat demand, see Figure 14a. As far as ATC is concerned (Figure 14b), heat demand and fuel price have a similar impact: ATC increased by $15 \%$ when the input parameter increases by $20 \%$. The price of electricity exhibits the opposite trend: the ATC is $12.5 \%$ higher when it decreases with $20 \%$, due to the lower revenues from the $\mathrm{CHP}$ unit. The price of $\mathrm{CO}_{2}$ and the interest rate should not be neglected, although they have a lower impact on ATC.

In terms of impact on the systems design in Figure $14 \mathrm{c}, \mathrm{d}$, the TES volume is less sensitive to the uncertainties on the inputs than the STC area, which significantly varies with heat demand, fuel price and interest rate. Although this study showed that their combination with TES can result in a profitable reduction of $\mathrm{CO}_{2}$ emissions, this shows that economic aspects can be a limiting factor in the implementation of STC. 


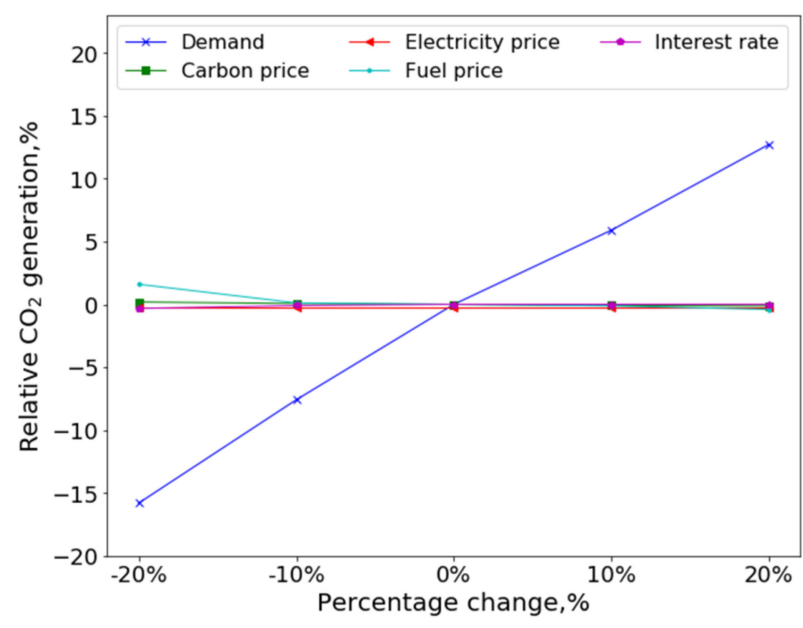

(a)

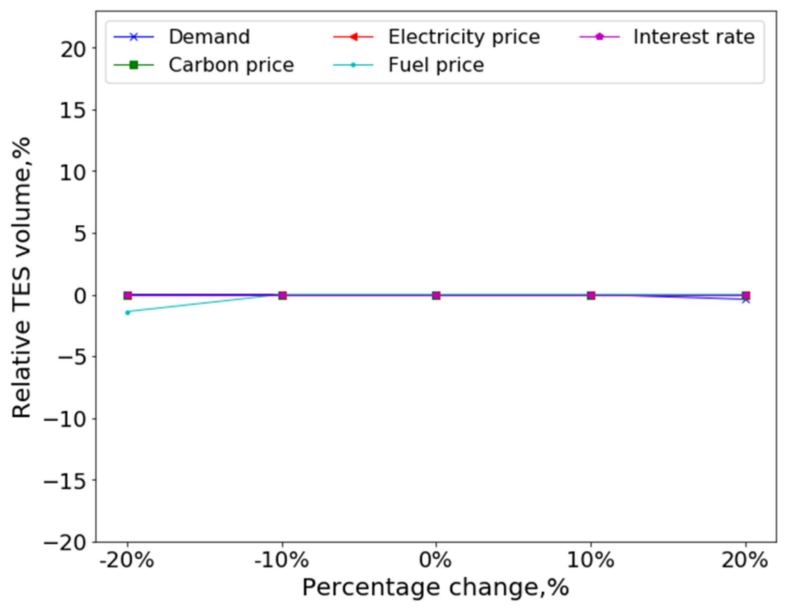

(c)

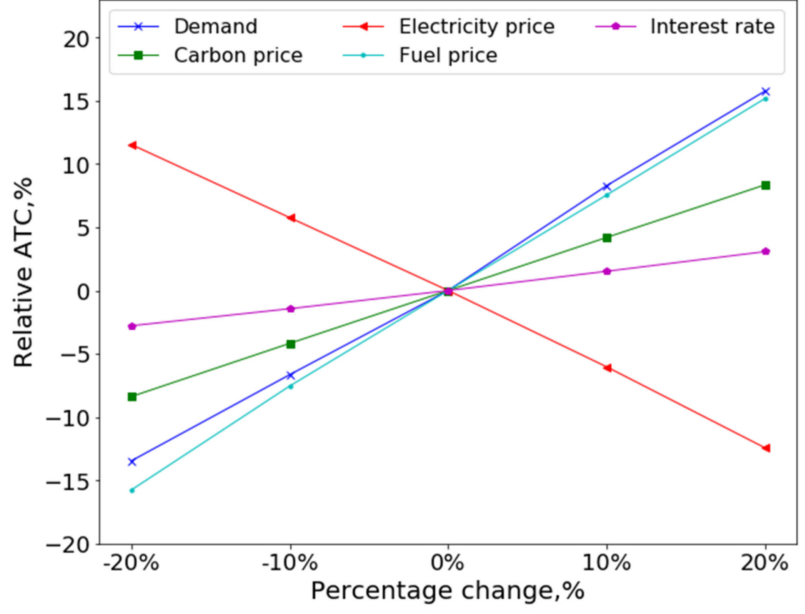

(b)

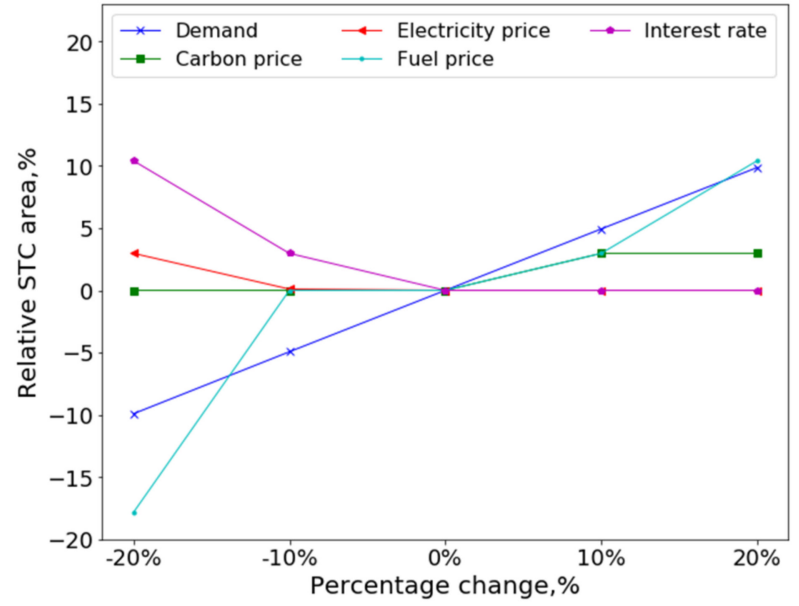

(d)

Figure 14. Sensitivity of the main results to the variation of key input parameters: (a) $\mathrm{CO}_{2}$ generation; (b) ATC; (c) TES volume; (d) STC area.

\section{Conclusions and Future Work}

A framework for the multi-objective optimization of the integration of Solar Thermal Collectors (STC) and Thermal Energy Storage (TES) systems in existing fossil-fuel based heat and power production systems was presented. The proposed method was applied to the representative case of a medium-scale CHP system coupled to a District Heating network. As a comparison, the integration of TES or STC alone was also considered.

The proposed TOPSIS-entropy method has been proved to be efficient to select the optimal design in terms of trade-off between cost and $\mathrm{CO}_{2}$ reduction. Our results show that, while the addition of TES or STC alone results in limited economic and environmental performances and exhibits a rapid increase of the cost with the targeted $\mathrm{CO}_{2}$ emission reduction, the optimal combination of TES and STC can lead to a reduction of both the cost and the $\mathrm{CO}_{2}$ emissions: respectively $3 \%$ and $10 \%$ in the studied case. For larger $\mathrm{CO}_{2}$ emissions savings, beyond the optimal trade-off, the additional cost remains limited compared to the other solutions. The integration of TES and STC also significantly improves the system flexibility and efficiency. TES allows for peak load shaving and load valley filling, resulting in up to $52 \%$ less operation of peak units. For the optimal design, the total efficiency of the system increases from $87 \%$ to $92 \%$. The share of renewable energy reaches $10 \%$ when both TES and STC are integrated, compared to 7\% with STC alone.

The operational flexibility of the CHP unit itself is also increased by the integration of TES and STC, which helps increasing the electrical power generation. 
A sensitivity analysis shows that only the heat demand has a significant impact on the environmental performance, while both the heat demand and the fuel price have a significant influence on the economic performances. Furthermore, the optimal TES volume is less sensitive to the uncertainties on the inputs than the STC surface, that is more impacted by the economic parameters.

In future works, the same methodology could be applied to the integration of more renewable energy sources such as heat pumps and power-to- $X$ based on renewable electricity production. The case of a new CHP unit will also be investigated instead of a retrofit, taking into account the optimal sizing of this unit and the related investment costs. Moreover, the impact of the uncertainties on the input data could be studied using advanced Uncertainty Quantification and Robust Design techniques.

Author Contributions: G.W.; conceptualization, data curation, methodology, software, formal analysis, investigation, writing —original draft, writing — review and editing, visualization. J.B.; conceptualization, methodology, investigation, writing — review and editing, supervision, project administration, funding acquisition. All authors have read and agreed to the published version of the manuscript.

Funding: The research received no external funding.

Informed Consent Statement: Informed consent was obtained from all subjects involved in the study.

Conflicts of Interest: The authors declare that they have no known competing financial interests or personal relationships that could have appeared to influence the work reported in this paper.

\section{Nomenclature}

\begin{tabular}{|c|c|}
\hline \multicolumn{2}{|l|}{ Abbreviations } \\
\hline ATC & Annual total cost \\
\hline $\mathrm{CHP}$ & Combined heat and power \\
\hline DES & Distributed energy system \\
\hline $\mathrm{DH}$ & District heating \\
\hline $\mathrm{EC}$ & Extraction condensation steam turbine \\
\hline $\mathrm{HOB}$ & Heat-only boiler \\
\hline MILP & Mixed-integer linear programming \\
\hline RES & Renewable energy source \\
\hline STC & Solar thermal collector \\
\hline TES & Thermal energy storage \\
\hline TOPSIS & Technique for Order Preference by Similarity to Ideal Solution \\
\hline \multicolumn{2}{|c|}{ Indices and sets } \\
\hline $\mathrm{u}$ & Unit index, $\mathrm{u} \in$ units \\
\hline $\mathrm{t}$ & Time index, $\mathrm{t} \in$ periods \\
\hline \multicolumn{2}{|l|}{ Parameters } \\
\hline $\mathrm{Cap}_{u}$ & Maximum capacity of each unit, MW. \\
\hline$c_{u}^{i n v}$ & Specific investment cost per hour, $€ / M W$ \\
\hline$c_{t}^{\text {invTES }}$ & Specific investment cost per hour for TES, $€ / \mathrm{m}^{3}$. \\
\hline$c_{t}^{i n v S T C}$ & Specific investment cost per hour for STC, $€ / \mathrm{m}^{2}$. \\
\hline$a_{u}$ & Annuity factor. \\
\hline$I_{u}^{i n v}$ & Specific Investment cost per unit, $€ / M W$ \\
\hline$I^{\text {invTES }}$ & Specific Investment cost per volume for TES $€ / \mathrm{m}^{3}$. \\
\hline$I^{i n v S T C}$ & Specific Investment cost per area for STC $€ / \mathrm{m}^{2}$ \\
\hline$c_{u, t}^{M}$ & Specific maintenance cost, $€ /(\mathrm{MW} \cdot \mathrm{h})$ \\
\hline$c_{t}^{M T E S}$ & Specific maintenance cost for $\mathrm{TES}, € /\left(\mathrm{m}^{3} \cdot \mathrm{h}\right)$. \\
\hline$c_{t}^{M S T C}$ & Specific maintenance cost for STC, $€ /\left(\mathrm{m}^{2} \cdot \mathrm{h}\right)$ \\
\hline$c_{u, t}^{f u e l}$ & Fuel cost, $€ / \mathrm{MWh}$ \\
\hline$S C_{u}$ & Start-up cost per time, $€$ \\
\hline$C F_{u}$ & Carbon emission factor for each fuel, $\mathrm{kg} \mathrm{CO}_{2} / \mathrm{MWh}$ \\
\hline$E l_{t}$ & Electricity price, $€ / M W h$ \\
\hline ramp_up $p_{u, t}$ & Maximum ramp up rate. \\
\hline ramp_down $n_{u, t}$ & Maximum ramp down rate. \\
\hline
\end{tabular}




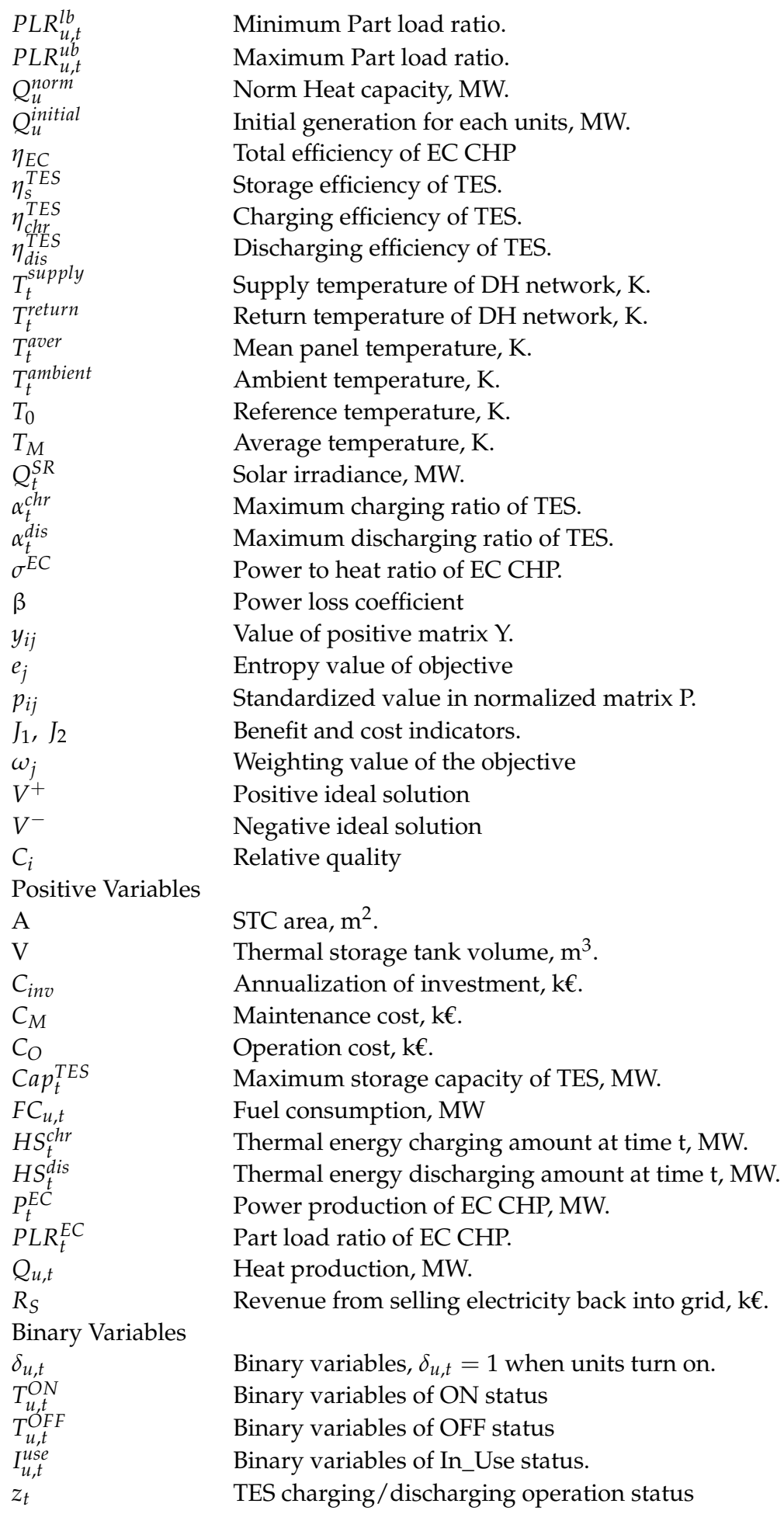

\section{References}

1. European Commission. Mapping and Analyses of the Current and Future (2020-2030). Heating/Cooling Fuel DeploymentExecutive Summary. Available online: https://energy.ec.europa.eu/mapping-and-analyses-current-and-future-2020-2030heatingcooling-fuel-deployment-fossilrenewables-1_en (accessed on 6 December 2021).

2. Eurostat. Renewable Energy Statistics. Available online: https: / / ec.europa.eu/eurostat $/$ statistics-explained $/$ index.php?title= Renewable_energy_statistics (accessed on 6 December 2021).

3. International Renewable Energy Agency. Renewable Energy in District Heating and Cooling. Available online: https://www. irena.org/publications/2017/Mar / Renewable-energy-in-district-heating-and-cooling (accessed on 6 December 2021).

4. Danish Energy Agency. Technology Data: Generation of Electricity and District Heating. Available online: https://ens.dk/sites/ ens.dk/files/Analyser/technology_data_catalogue_for_el_and_dh.pdf (accessed on 6 December 2021). 
5. Verkis Svartsengi. Power Plant. Available online: https://www.verkis.com/projects/energy-production/geothermal-energy/ nr/936 (accessed on 6 December 2021).

6. International Energy Agency (IEA). Large Biomass CHP Plant in Stockholm, Sweden. Available online: https://www.ieabioenergy. com/wp-content/uploads/2018/02/8-LargeCHP-Va\%CC\%88rtaverket_SE_Final.pdf (accessed on 6 December 2021).

7. Lund, H.; Østergaard, P.A.; Connolly, D.; Ridjan, I.; Mathiesen, B.V.; Hvelplund, F.; Thellufsen, J.Z.; Sorknsæs, P. Energy Storage and Smart Energy Systems. Int. J. Sustain. Energy Plan. Manag. 2016, 11, 3-14. [CrossRef]

8. Lund, H.; Werner, S.; Wiltshire, R.; Svendsen, S.; Thorsen, J.E.; Hvelplund, F.; Mathiesen, B.V. 4th Generation District Heating (4GDH). Integrating Smart Thermal Grids into Future Sustainable Energy Systems. Energy 2014, 68, 1-11. [CrossRef]

9. Cabeza, L.F.; Miró, L.; Oró, E.; De Gracia, A.; Martin, V.; Krönauer, A.; Rathgeber, C.; Farid, M.M.; Paksoy, H.O.; Martínez, M.; et al. $\mathrm{CO}_{2}$ Mitigation Accounting for Thermal Energy Storage (TES) Case Studies. Appl. Energy 2015, 155, 365-377. [CrossRef]

10. Benalcazar, P. Optimal Sizing of Thermal Energy Storage Systems for CHP Plants Considering Specific Investment Costs: A Case Study. Energy 2021, 234, 121323. [CrossRef]

11. Mugnini, A.; Comodi, G.; Salvi, D.; Arteconi, A. Energy Flexible CHP-DHN Systems: Unlocking the Flexibility in a Real Plant. Energy Convers. Manag. X 2021, 12, 100110. [CrossRef]

12. Lai, F.; Wang, S.; Liu, M.; Yan, J. Operation Optimization on the Large-Scale CHP Station Composed of Multiple CHP Units and a Thermocline Heat Storage Tank. Energy Convers. Manag. 2020, 211, 112767. [CrossRef]

13. Savic, D. Single-Objective vs. Multiobjective Optimisation for Integrated Decision Support. In Proceedings of the First Biennial Meeting of the International Environmental Modelling and Software Society, Lugano, Switzerland, 24-27 June 2002; pp. 7-12.

14. Ren, H.; Zhou, W.; Nakagami, K.; Gao, W.; Wu, Q. Multi-Objective Optimization for the Operation of Distributed Energy Systems Considering Economic and Environmental Aspects. Appl. Energy 2010, 87, 3642-3651. [CrossRef]

15. Fazlollahi, S.; Becker, G.; Ashouri, A.; Maréchal, F. Multi-Objective, Multi-Period Optimization of District Energy Systems: IV—A Case Study. Energy 2015, 84, 365-381. [CrossRef]

16. Luo, Z.; Yang, S.; Xie, N.; Xie, W.; Liu, J.; Souley Agbodjan, Y.; Liu, Z. Multi-Objective Capacity Optimization of a Distributed Energy System Considering Economy, Environment and Energy. Energy Convers. Manag. 2019, 200, 112081. [CrossRef]

17. Karmellos, M.; Mavrotas, G. Multi-Objective Optimization and Comparison Framework for the Design of Distributed Energy Systems. Energy Convers. Manag. 2019, 180, 473-495. [CrossRef]

18. Franco, A.; Versace, M. Multi-Objective Optimization for the Maximization of the Operating Share of Cogeneration System in District Heating Network. Energy Convers. Manag. 2017, 139, 33-44. [CrossRef]

19. Wirtz, M.; Hahn, M.; Schreiber, T.; Müller, D. Design Optimization of Multi-Energy Systems Using Mixed-Integer Linear Programming: Which Model Complexity and Level of Detail Is Sufficient? Energy Convers. Manag. 2021, 240, 114249. [CrossRef]

20. Wu, Q.; Ren, H.; Gao, W.; Ren, J. Multi-Objective Optimization of a Distributed Energy Network Integrated with Heating Interchange. Energy 2016, 109, 353-364. [CrossRef]

21. Verbruggen, A.; Dewallef, P.; Quoilin, S.; Wiggin, M. Unveiling the Mystery of Combined Heat \& Power (Cogeneration). Energy 2013, 61, 575-582. [CrossRef]

22. Mollenhauer, E.; Christidis, A.; Tsatsaronis, G. Evaluation of an Energy- and Exergy-Based Generic Modeling Approach of Combined Heat and Power Plants. Int. J. Energy Environ. Eng. 2016, 7, 167-176. [CrossRef]

23. Wang, H.; Yin, W.; Abdollahi, E.; Lahdelma, R.; Jiao, W. Modelling and Optimization of CHP Based District Heating System with Renewable Energy Production and Energy Storage. Appl. Energy 2015, 159, 401-421. [CrossRef]

24. Sveinbjörnsson, D.; Jensen, L.L.; Trier, D.; Bava, F.; Hassine, I.B.; Jobard, X. Fifth Generation, Low Temperature, High Exergy District Heating and Cooling Networks: D2.3 Large Storage Systems for DHC Networks. Available online: https: / / ec.europa.eu/research/participants / documents/downloadPublic?documentIds=080166e5c2089739\&appId=PPGMS (accessed on 6 December 2021).

25. Schmidt, T.; Miedaner, O. Solar District Heating Guidelines. Available online: https://www.solarthermalworld.org/sites/ default/files/story /2015-04-03/sdh-wp3-d31-d32_august2012_0.pdf (accessed on 6 December 2021).

26. Chen, P. Effects of the Entropy Weight on TOPSIS. Expert Syst. Appl. 2021, 168, 114186. [CrossRef]

27. Li, X.; Wang, K.; Liuz, L.; Xin, J.; Yang, H.; Gao, C. Application of the Entropy Weight and TOPSIS Method in Safety Evaluation of Coal Mines. Procedia Eng. 2011, 26, 2085-2091. [CrossRef]

28. Ding, L.; Shao, Z.; Zhang, H.; Xu, C.; Wu, D. A Comprehensive Evaluation of Urban Sustainable Development in China Based on the TOPSIS-Entropy Method. Sustainability 2016, 8, 746. [CrossRef]

29. Epexspot. EPEX SPOT 2021. Available online: https://www.epexspot.com/en (accessed on 6 December 2021).

30. European Commission. JRC Photovoltaic Geographical Information System (PVGIS)—Commission. Available online: https: / / re.jrc.ec.europa.eu/pvg_tools/en/\#MR (accessed on 6 December 2021).

31. Benalcazar, P. Sizing and Optimizing the Operation of Thermal Energy Storage Units in Combined Heat and Power Plants: An Integrated Modeling Approach. Energy Convers. Manag. 2021, 242, 114255. [CrossRef]

32. Morvaj, B.; Evins, R.; Carmeliet, J. Optimising Urban Energy Systems: Simultaneous System Sizing, Operation and District Heating Network Layout. Energy 2016, 116, 619-636. [CrossRef]

33. Fazlollahi, S.; Becker, G.; Maréchal, F. Multi-Objectives, Multi-Period Optimization of District Energy Systems: II-Daily Thermal Storage. Comput. Chem. Eng. 2014, 71, 648-662. [CrossRef] 
34. Limpens, G.; Moret, S.; Jeanmart, H.; Maréchal, F. EnergyScope TD: A Novel Open-Source Model for Regional Energy Systems. Appl. Energy 2019, 255, 113729. [CrossRef]

35. Quaschning, V. Understanding Renewable Energy Systems; Routledge: Abingdon, UK, 2005; Volume 67, ISBN 9781844071289.

36. Worldbank. Carbon Pricing Dashboard, Up-to-Date Overview of Carbon Pricing Initiatives. Available online: https:// carbonpricingdashboard.worldbank.org/map_data (accessed on 6 December 2021).

37. Akbari, K.; Nasiri, M.M.; Jolai, F.; Ghaderi, S.F. Optimal Investment and Unit Sizing of Distributed Energy Systems under Uncertainty: A Robust Optimization Approach. Energy Build. 2014, 85, 275-286. [CrossRef] 